\title{
Psychological

\section{Psychological problems among the Palestinian University students on the West Bank}

\author{
Filasteen Ismail Nazzal*, Orlanda Maria da Silva Rodrigues da Cruz and \\ Félix Fernando Monteiro Neto \\ Faculdade de Psicologia e de Ciencias da Educacao da Universidade do Porto, Porto, Portugal
}

\section{ABSTRACT}

The aim of this study was to investigate the prevalence of psychological problems among Palestinian university students on the West Bank. The sample consisted of 254 volunteer undergraduate students (50.4\% males and 49.6\% females). Data was collected using Psychological Problems Scale, Multidimensional Scale of Perceived Social Support (MSPSS), and a Demographic Information Form. The study showed that anxiety score $(M=2.83 ; S D=.92)$ was significantly higher than depression $(M=2.55 ; S D=.95)$, and psychosomatic symptoms $(M=2.57 ; S D=.87)$ scores. Anxiety and psychosomatic symptoms were significantly higher among female students than males. Furthermore, anxiety and depression were negatively correlated with perceived social support from friends, family and significant others.

KEY WORDS: ANXIETY, DEPRESSION, PSYCHOSOMATIC SYMPTOMS, SOCIAL SUPPORT, UNIVERSITY STUDENTS, PALESTINE

\section{INTRODUCTION}

Palestine is one of the Middle East countries which have been exposed to military violence and human rights abuse since 1948 (Punamäki, et al., 2005). This study focuses on the psychological problems among Palestinian university students on the West Bank as a result of traumatic life events. Several studies indicate high prevalence of mental health problems among university and college students and it is increasing concern worldwide. While in university young adults have to face and adapt to a new and challenging social networks which may contribute to turn they more vulnerable for developing mental health problems Also the traumatic life events

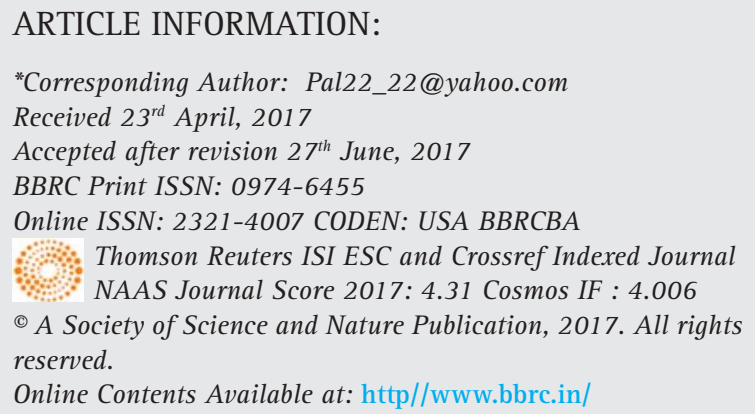


resulting from the Israeli occupation, such as killing, demolition of homes, bombing and destruction, lead to depression, anxiety, post-traumatic stress disorder and other mental disorders among Palestinian people (Assaf, 2002, Zivin, et al., 2009 and Saleem et al., 2013). Perceived social support is an important factor for reducing psychological problems. Several studies have found an association between low levels of social support and poor mental health (Duru, 2007; Oni, 2010). For example, lack of social support is one of the independent risk factor for depression, meaning that the students who had low social support had higher depression. However, social support has buffering effects on depression among university students (Laurence, Williams, \&t Eiland, 2009; Oni, 2010 and Chia \&t Graves, 2016).

In relation to gender, some studies suggest that female students score higher than male students in depression and anxiety (Bayram \&t Bilgel, 2008; Dyrbye, 2006; Raypa, 2012; Rosenthal, 2000). However other scholars found no gender differences on depression among university students (Alansari, 2006; Dorahy, 2000; Hamdan-Mansou et al., 2009). Some studies found that the educational strategies that used by the cultural and sometimes parenting styles may be related to anxiety, depression and other mental health problems as well (Abadsa \&t Thabet, 2012).

Several studies suggest high rates depression and anxiety, among university students all over the world and especially in Turkey (Bayram, 2008; Chia \&t Graves, 2016; Daniel, 2013; Jenkins, 2013; Ovuga, Boardman, \&t Wasserman, 2006; Wong et al., 2006), 8\% of university students had depressive feelings in Jordan (HamdanMansour \&t Marmash, 2007), 75\% of the university students had some degree of depressive symptoms in Jordan (Hamdan-Mansour et al., 2009). 27.5\% of students had depressive symptoms and anxiety in Hong Kong (Wong et al., 2006). 15.6\% undergraduate's students had depressive or anxiety disorder in U.S.A (Eisenberg, Gollust, Golberstein, \& Hefner, 2007), third of the students had mental health problems in U S A (Zivin et al., 2009), in Malaysia 34.4\% of university students showed mental health problems (Nordin, Abu Talib, \& Yaacob, 2009 Chia \&t Graves, 2016).

Even though there is high prevalence of psychological problems among university students, there are a few studies about the prevalence of psychological problems in Palestine, however Abadsa and Thabet (2012) found higher prevalence of depression, anxiety and PTSD adult population in Gaza in Palestine. The aim of the current study was to investigate the prevalence of psychological problems among Palestinian university students on the West Bank according to gender, age, faculty, university, parental education level, monthly family income and place of residence. Based on the literature reviewed above, we advance one research question (RQ1) and three hypotheses.

$R Q 1$ : Are there significant differences in the degree of psychological problems according to gender, age, faculty, university, family income, parents' level of education, and place of residence?

Hypothesis 1: There will be a significant negative correlation between anxiety and perceived social support from friends, family and significant others. Hypothesis 2: There will be a significant negative correlation between depression and perceived social support from friends, family, and significant others.

Hypothesis 3: There will be a significant negative correlation between psychosomatics symptoms and perceived social support from friends, family, and significant others.

\section{MATERIAL AND METHODS}

Data from 254 (126 females and 128 males) undergraduate students from two universities on the West Bank in Palestine were used in this study. The age of the participants ranged from 18 to 26 years, $41.3 \%$ of participants were 18 to 21 years and $58.7 \%$ were 22 to 26 years of age. Eighty seven percent were attending the An-Najah National University and 19.3\% were attending the Arab American University, $27 \%$ were attending a course in sciences and 73\% in humanities. Regarding parental education, $20.1 \%$ of the parents did not finish secondary school, 37.4\% hold secondary school, and 42.5\% hold a bachelor degree or higher. Regarding monthly family income, about 37\% of the participants' families had a monthly income ranging between 500-1000 USD. Furthermore, $52.4 \%$ of the participants were living in villages, about $42.5 \%$ in cities, and 5.1\% in refugee camps. More than $89.8 \%$ of the participants' families had their own houses (See Table 1).

Three self-report instruments were used to collect data: Psychological Problems Scale (Berry et al., 2006; Neto, 2009), Multidimensional Scale of Perceived Social Support (MSPSS; Zimet, Dahlem, Zimet, S \& Farley, 1988), and Demographic Information Form.

Psychological problems scale. This scale consists of 15 items and was designed to measure depression, anxiety and psychosomatic symptoms (Berry et al., 2006; Neto, 2009). Participants responded on a 5-point Likert-type scale ranging from 1 (strongly disagree) to 5 (strongly agree).

Multidimensional Scale of Perceived Social Support (MSPSS). The MSPSS was developed by Zimet, et al. (1988). It is a 12-item scale that measures perceived support from three domains: family (FA), friends (FR), and a significant others (SO). Participants completed the 


\begin{tabular}{|c|c|c|c|}
\hline \multicolumn{2}{|l|}{ Demographic variables } & \multirow{2}{*}{$\begin{array}{l}\text { Frequency } \\
128\end{array}$} & \multirow{2}{*}{$\begin{array}{l}\text { Percentage } \\
50.4\end{array}$} \\
\hline Gender & Males & & \\
\hline & Females & 126 & 49.6 \\
\hline \multirow[t]{2}{*}{ Age } & $18-21$ & 105 & 41.3 \\
\hline & $22-26$ & 149 & 58.7 \\
\hline \multirow[t]{3}{*}{ Parental Educational levels } & Less than secondary & 51 & 20.1 \\
\hline & Secondary & 95 & 37.4 \\
\hline & Bachelor and more & 108 & 42.5 \\
\hline \multirow[t]{3}{*}{ Monthly Family Income } & $500 \$$ and less & 77 & 30.3 \\
\hline & $500-1000 \$$ & 94 & 37.0 \\
\hline & More than $1000 \$$ & 79 & 31.5 \\
\hline \multirow[t]{3}{*}{ Place of Residence } & Village & 133 & 52.4 \\
\hline & City & 108 & 42.5 \\
\hline & Refugee camp & 13 & 5.1 \\
\hline \multirow[t]{2}{*}{ University } & An-Najah & 205 & 80.7 \\
\hline & Arab American & 49 & 19.3 \\
\hline \multirow[t]{2}{*}{ Faculty } & Sciences & 68 & 26.8 \\
\hline & Humanities & 185 & 72.8 \\
\hline
\end{tabular}

MSPSS items on a 7-point Likert-type scale, ranging from 1 (strongly disagree) to 7 (strongly agree). We used the Arabic version of MSPSS adapted by Abou-hashem (2010) in Egypt. A Chronbach alpha .89 was found for the total scale, .83 for friends support, .78 for family support, and .81 for significant others support.

Demographic Information Form. This form was used to obtain detailed information on basic demographics such as age, gender, family income, parents' level of education, housing conditions, university, faculty, and place of residence.

Informed consent was obtained from all participants before completing the measures. Participants were assured of the confidentiality of their responses. The questionnaires were presented in Arabic to all participants. This was considered an adequate procedure as all participants were fluent in Arabic. It took approximately 15 minutes to complete the full set of questionnaires. Data were analyzed using descriptive statistics, independent sample $t$-test and one-way ANOVA to test differences among groups defined by sociodemographic variables, and bivariate correlation analysis to examine the association between anxiety, depression and psychosomatic symptoms, and perceived social support.

\section{RESULTS AND DISCUSSION}

We performed a principal component analysis to explore the structure of the psychological problems scale. Three eigenvalues were greater than one, and scree test also suggested the extraction of three factors. Table 2 shows the varimax-rotated, exploratory factor analysis. The first factor contains five items expressing Anxiety; alpha coefficient is .76. The second factor includes also five items expressing Depression; alpha coefficient is .81. The third factor is composed by four items expressing psychosomatic symptoms. Since item 15 loaded >. 40 on the first factor and on the third factor, it was exclude from further analysis alpha is .68.

Means and standard deviations for the major study variables are presented in Table 3. Results show that there was a statistically significant difference in anxiety according to gender, $t(252)=-2.84, p<0.01$, female students showed higher anxiety than male. Psychosomatic symptoms was also higher in female than male students, $t(252)=-3.75, p<0.01$. There was no statistically significant gender differences in depression, $t(252)=-1.01$, $p>0.05$, and in perceived social support from friends, $t(252)=-1.28, p>0.05$. Females presented higher perceived social support from family, $t(252)=-2.54, p<$ 0.05 , and from significant others, $t(252)=-3.96 p<0.01$ than males.

Concerning age, there was no significant differences between 18 to 21 and 22 to 26 age groups in anxiety, $t$ $(252)=1.14, p>0.05$, psychosomatic symptoms, $t(252)$ $=.64, p>0.05$ and depression, $t(252)=-.60, p>0.05$. There was no significant differences between students university affiliation in anxiety, $t(252)=-1.23, p>0.05$, psychosomatic symptoms, $t(252)=-1.0, p>0.05$ and 


\begin{tabular}{|l|l|l|l|}
\hline \multicolumn{5}{|l|}{ Table 2 Varimax Rotated Three Factors Solution of the Psychological Problems Scores } \\
\hline Items & Factor 1 & Factor 2 & Factor 3 \\
\hline & Anxiety & Depression & Psychosomatic symptoms \\
\hline 1. & .63 & & \\
\hline 2. & .64 & & \\
\hline 3. & .68 & & \\
\hline 4. & .61 & & \\
\hline 5. & .66 & & \\
\hline 6. & & .57 & \\
\hline 7. & & .79 & \\
\hline 8. & & .60 & \\
\hline 9. & & .75 & \\
\hline 10. & & .69 & \\
\hline 11. & & & .56 \\
\hline 12. & & & .77 \\
\hline 13. & & & .77 \\
\hline 14. & & & .56 \\
\hline 15. & & & .45 \\
\hline Eigenvalue & 5.43 & 1.78 & 1.03 \\
\hline Explained Variance & 36.20 & 11.71 & 6.69 \\
\hline
\end{tabular}

depression, $t(252)=.07, p>0.05$. However there were significant differences according to parental education level in anxiety, $F(2,251)=4.38, p<0.05$, psychosomatic symptoms, $F(2,251)=3.52, p<0.05$, and depression, $F(2,251)=4.78, p<0.01$.

To test the hypotheses 1,2 and 3 correlation analyses were conducted (See Table 4). The findings indicate that there were significant correlations among anxiety, depression, perceived social support from friend, family and significant others $(p<0.05)$. More specifically there was a strong positive correlation between anxiety and depression $(r=61)$, a moderate positive correlation between anxiety and psychosomatic symptoms $(r=.49)$, and moderate negative correlations between depression and support from friends ( $r=-.32)$, family ( $r=-.33$ ), and significant others $(r=-.36)$. There were modest negative correlations between anxiety and support from friends $(r$ $=-.17)$, family $(r=-.16)$, and significant others $(r=-.15)$.

The current study was designed to investigate the prevalence of psychological problems among Palestinian university students on the West Bank. The study showed that the mean scores for anxiety was 2.83 , for depression was 2.55 and for psychosomatic symptoms was 2.57. It can be observed that these values are below the midpoint of the scale $(<3)$.Anxiety and psychosomatic symptoms were statistically higher in females than in males. This result is supported by some previous studies in Gaza (Abadsa \&t Thabet, 2012), Turkey (Bayram

Table 3. Descriptive Statistics of the Major Study Variables, and Independent Sample t-Test Performance
Scores of Students with Gender.
\begin{tabular}{|l|l|l|l|l|l|l|}
\hline & $\begin{array}{l}\text { Total n=254 } \\
\text { M(SD) }\end{array}$ & Min-Max & $\begin{array}{l}\text { Male n=128 } \\
\text { M(SD) }\end{array}$ & $\begin{array}{l}\text { Female n=126 } \\
\text { M(SD) }\end{array}$ & t & Sig \\
\hline Anxiety & $2.83(.92)$ & $1-5$ & $2.67(.82)$ & $2.99(.98)$ & -2.84 & .01 \\
\hline Depression & $2.55(.95)$ & $1-5$ & $2.49(.84)$ & $2.61(1.05)$ & -1.01 & .31 \\
\hline $\begin{array}{l}\text { Psychosomatic } \\
\text { symptoms }\end{array}$ & $2.57(.87)$ & $1-5$ & $2.37(.74)$ & $2.77(.94)$ & -3.75 & .00 \\
\hline Friends support & $20.4(4.70)$ & $4-28$ & $20.1(4.9)$ & $20.8(4.5)$ & -1.28 & .20 \\
\hline Family support & $21.6(4.72)$ & $4-28$ & $20.9(4.7)$ & $22.3(4.7)$ & -2.54 & .01 \\
\hline $\begin{array}{l}\text { Significant others } \\
\text { support }\end{array}$ & $21.9(4.80)$ & $4-28$ & $20.8(5.0)$ & $23.1(4.3)$ & -3.96 & .00 \\
\hline Perceived social support & $64.0(11.9)$ & $16-84$ & $61.7(12.3)$ & $66.3(11.0)$ & -3.11 & .00 \\
\hline
\end{tabular}




\begin{tabular}{|l|l|l|l|l|l|}
\hline Table 4. Correlations Among Variables $(\mathrm{n}=254)$. \\
\hline & 1 & 2 & 3 & 4 & 5 \\
\hline 1. Anxiety & & & & & \\
\hline 2. Depression & $.61^{* * * *}$ & & & & \\
\hline 3. Psychosomatic symptoms & $.49^{* * * *}$ & .32 & & & \\
\hline 4. Friends support & $-.17^{* *}$ & $-.32^{* * *}$ & .02 & & \\
\hline 5. Family support & $-.16^{*}$ & $-.33^{* * *}$ & .01 & $.49^{* * * *}$ & \\
\hline 6. Significant others support & $-.15^{*}$ & $-.36^{* * *}$ & .00 & $.58^{* * * *}$ & $.57^{* * *}$ \\
\hline${ }^{*} \mathrm{p}<.05^{* *} \mathrm{p}<.01 .{ }^{* * *} \mathrm{p}<0.001$. \\
\hline
\end{tabular}

\&t Bilgel, 2008), U S A and Canada (Dyrbye, Thomas, \&t Shanafelt, 2006), U.S.A (Jenkins et al., 2013; Rosenthal Et Schreiner, 2000; Ryba \&t Hopko, 2012).

In Palestine, being an Arabic country, females get used to stay close with their mothers almost all the time since childhood. As a result, they are given less responsibility and freedom than males. Females reported higher dependence on their families than males. University life challenges females' sense of independence more than males and, as a result, they report high levels of anxiety and psychosomatic symptom. This result suggests that universities need to consider specific issues and strategies to improve female students' well-being (Alansari, 2006).

On the other hand no significant gender differences were found on depression among university students. This result is supported by some previous studies in Lebanon, Tunisia, Palestine, U.A. Emirates, Yemen, Jordan, and Sudan (Alansari, 2006), Palestine (Assaf, 2002), Turkey (Bayram \&t Bilgel, 2008), Australian, Ghanaian, Nigerian, Northern Irish, and Swaziland (Dorahy, 2000), and in Jordan (Hamdan-Mansou et al., 2009). However Abadsa and Thabet (2012) found that depression were statistically higher in females than in males in Gaza.

As hypothesized, the results showed that between anxiety and depression was negatively and significantly related to perceived social support from friends, family and significant others. This means that when perceived social support increases, anxiety and depression decreases. When people perceive a good support from their social network they will experience less psychological problems than others with low perceived social support from their social network. it is happened also with the university students who reported lower levels of supportive from their social network also reported higher levels of anxiety and depression, that anxiety and depression are related (Serin, Serin \&t Özbaş, 2010; Zhou, 2013). Perceived social support, depression, and anxiety among university students are highly interrelated and it may contribute of improving their psychological and social life (Guney, Kalafat \& Boysan, 2010).

Thus, the rise in perceived social support from friends, family, and significant others will lead to low level of anxiety and depression and other psychological problems, improving psychological wellbeing among students. Psychological counseling centers at universities have a lot of responsibilities and activities in helping students who need psychological counseling. Local institutions and associations will also help in cooperation with the universities in their common activities (Alansari, 2006; Laurence, et al., 2009; Zhou, 2013).

\section{REFERENCES}

Abadsa, A. and Thabet, A. (2012). Mental health problems among Palestinian university students in the Gaza Strip. Arab Psychological E. Journal, 34-35, 220-226.

Abou-Hashem, M. (2010). Structure model relations between psychological well- being and big five personality factors and self-esteem and social support to university students. Journal of Faculty of Education, 20 (81), 269-350.

Alansari, B. M. (2006). Gender differences in depression among undergraduates from seventeen Islamic countries. Social Behavior and Personality: An International Journal, 34(6), 729-738.

Assaf, A. (2002). The perception of student psychological problems at An-Najah National University through the Al-Aqsa Intifada as a result of Israeli occupation. An-Najah University Journal for Research (Humanities), 19, 221-254.

Bayram, N., and Bilgel, N. (2008). The prevalence and sociodemographic correlations of depression, anxiety and stress among a group of university students. Social Psychiatry and Psychiatric Epidemiology, 43(8), 667-672. doi 10.1007/s00127008-0345-X.

Berry, J. W., Phinney, J. S., Sam, D. L., and Vedder, P. (2006). Immigrant youth in cultural transition: Acculturation identity and adaptation across national contexts. Mahwah, NJ: Erlbaum.

Chia, A. L. and Graves, R. (2016). Examining anxiety and depression co morbidity among Chinese and European Canadian university students. Journal of Cross-Cultural Psychology, 47(2), 215-233. doi: 10.1177/0022022115618025.

Daniel, K. (2013). Loneliness and depression among university students in Kenya. Global Journal of Human-Social Science Research, 13(4), 10-18. Online ISSN: 2249-460x \& Print ISSN: 0975-587X. 
Dorahy, M. J., Lewis, C. A., Schumaker, J. F., AkuamoahBoateng, R., Duze, M. C., and Sibiya, T. E. (2000). Depression and life satisfaction among Australian, Ghanaian, Nigerian, Northern Irish, and Swazi university students. Journal of Social Behavior and Personality, 15(4), 569-580.

Duru, E. (2007). Re-examination of the psychometric characteristics of the multidimensional scale of perceived social support among Turkish university students. Social Behavior and Personality: An International Journal, 35(4), 443-452.

Dyrbye, L. N., Thomas, M. R., and Shanafelt, T. D. (2006). Systematic review of depression, anxiety, and other indicators of psychological distress among US and Canadian medical students. Academic Medicine, 81(4), 354-373.

Guney, S., Kalafat, T., \&t Boysan, M. (2010). Dimensions of mental health: life satisfaction, anxiety and depression: a preventive mental health study in Ankara University students population. Procedia-Social and Behavioral Sciences, 2(2), 1210-1213. doi:10.1016/j.sbspro.2010.03.174.

Hamdan-Mansour, A. M., Halabi, J. O., \&t Dawani, H. A. (2009). Depression, hostility, and substance use among university students in Jordan. Mental Health and Substance Use: Dual Diagnosis, 2(1), 52-63. doi: 10.1080/17523280802593301.

Hamdan-Mansour, A., \&t R Marmash, L. (2007). Health concerns and risk behaviors among university students in Jordan. Jordan Medical Journal, 41(2), 80-89.

Jenkins SR Belaqnger A., Conally ML., Boals, A., and Duron KM (2013) First generation undergraduate students social support and life satisfaction Journal of College Counselling 16 (2) 129-142

Laurence B., Williams C., and Eiland D (2009) Depressive symptoms stress and social support among dental students at a historically Black college and University Journal of American College Health 58 (1) 56-63

Jenkins, S. Laurence, B. Neto, F. (2009). Predictors of mental health among adolescents from immigrant families in Portugal. Journal of Family Psychology, 23(3), 375-385. doi.10.1037/ a0015831.

Neto F., (2009) Predictors of mental health among adolescents from immigrant families in Portugal Journal of Family Psychology 23 (3) 375-385

Nordin, N., Abu Talib, M., \&t Yaacob, S. N. (2009). Personality, loneliness and mental health among undergraduates at Malay- sian Universities. European Journal of Scientific Research, 36(2), 285-298. ISSN 1450-216X

Oni, 0. 0. (2010). Social support, loneliness and depression in the elderly. Unpublished master's thesis, Queen's University Kingston, Ontario, Canada. Retervied from http://qspace. library.queensu.ca/dspace/bitstream/1974/6047/1.pdf. on 112-15.

Ovuga, E., Boardman, J., \&t Wasserman, D. (2006). Undergraduate student mental health at Makerere University, Uganda. World Psychiatry, 5(1), 51-52.

Punamäki, R. L., Komproe, I. H., Qouta, S., Elmasri, M., \&t de Jong, J. T. (2005). The role of peritraumatic dissociation and gender in the association between trauma and mental health in a Palestinian community sample. American Journal of Psychiatry, 162(3), 545-551.

Ryba, M. M., \&t Hopko, D. R. (2012). Gender differences in depression: Assessing meditational effects of overt behaviors and environmental reward through daily diary monitoring. Depression Research and Treatment, 2012, 1-10. doi:10.1155/2012/865679.

Saleem, S., Mahmood, Z., \&t Naz, M. (2013). Mental health problems in university students: A prevalence study. FWU Journal of Social Sciences, 7(2), 124-130.

Serin, N. B., Serin, O., \&t Özbaş, L. F. (2010). Predicting university students' life satisfaction by their anxiety and depression level. Procedia-Social and Behavioral Sciences, 9, 579-582. doi:10.1016/j.sbspro.2010.12.200.

Wong, J. G., Cheung, E. P., Chan, K. K., Ma, K. K., \& Wa Tang, S. (2006). Web-based survey of depression, anxiety and stress in first-year tertiary education students in Hong Kong. Australian and New Zealand Journal of Psychiatry, 40(9), 777-782. doi: 10.1080/j.1440-1614.2006.01883.

Zhou, X., Zhu, H., Zhang, B., \&t Cai, T. (2013). Perceived social support as moderator of perfectionism, depression, and anxiety in college students. Social Behavior and Personality: An International Journal, 41(7), 1141-1152. doi:10.

Zimet, G. D., Dahlem, N. W., Zimet, S. G. \& Farley, G. K. (1988). The Multidimensional Scale of Perceived Social Support. Journal of Personality Assessment, 52(1), 30-41.

Zivin, K., Eisenberg, D., Gollust, S. E., \&t Golberstein, E. (2009). Persistence of mental health problems and needs in a college student population. Journal of Affective Disorders, 117(3), 180-185. doi:10.1016/j.jad.2009.01.001 